\title{
Carta resposta referente ao artigo "Etnia Asiática: um fator de risco para a capsulite adesiva?"
}

\section{Answer to letter to the editor regarding the article "Asian ethnicity: a risk factor for adhesive capsulitis?”}

\author{
Eduardo Angeli Malavolta ${ }^{1}$ Mauro Emilio Conforto Gracitelli ${ }^{1}$ Jorge Henrique Assunção ${ }^{1}$ \\ Arnaldo Amado Ferreira Neto ${ }^{1}$
}

${ }^{1}$ Grupo de Ombro e Cotovelo, Instituto de Ortopedia e Traumatologia, Hospital das Clinicas, Faculdade de Medicina, Universidade de São Paulo, São Paulo, SP, Brasil

Address for correspondence Eduardo Malavolta, PhD, Rua Dr. Ovídio Pires de Campos 333, $3^{\circ}$ andar, Cerqueira Cesar, São Paulo/SP, Brazil, CEP 05403-010 (e-mail: eduardomalavolta@gmail.com).

Rev Bras Ortop 2019;54:358-359.

A capsulite adesiva acomete $13,5 \%$ dos pacientes que buscam atendimento de um ortopedista especialista em ombro, configurando o segundo diagnóstico mais frequente, após as afecções do manguito rotador. ${ }^{1}$ Entretanto, sua causa ainda é desconhecida. Boa parte da pesquisa sobre o tema se refere à busca de fatores de risco para o desenvolvimento da doença. A influência racial é pouco estudada como um fator envolvido no desenvolvimento da capsulite adesiva. Etnia branca $^{2}$ e nascimento nas ilhas britânicas ${ }^{3}$ já foram descritos como fatores de risco, mas informações sobre as demais etnias são uma lacuna na literatura. E é essa lacuna que nosso estudo ${ }^{4}$ visa ajudar a preencher.

Concordamos com algumas das críticas apresentadas. 0 estudo foi denominado como transversal para ressaltar que a avaliação dos pacientes ocorreu em tempo único, transversalmente, não sendo retrospectivo ou prospectivo. Entretanto, a terminologia mais adequada, e compativel com toda a análise estatística realizada, seria caso-controle. Avaliamos se a presença ou ausência de doença (capsulite adesiva) está ou não relacionada à exposição (ser ou não de etnia asiática), corrigindo a razão de chances para possíveis fatores confundidores por meio de uma regressão logística. Além disso, o intuito do estudo não foi avaliar a prevalência da doença, mas sim o risco em desenvolver a doença decorrente de uma exposição. Cabe ressaltar que a tempo-

\footnotetext{
(1)Eduardo Malavolta's ORCID is https://orcid.org/0000-0003-19566445.
}

received

April 23, 2019

accepted

May 7, 2019 ralidade de um fator de risco é motivo de discussão na escolha entre um desenho transversal (definindo a razão de prevalência) ou caso-controle (definindo a razão de chances). Devido ao fato do fator estudado (etnia) ser intrínseco à pessoa e presente desde o nascimento, consideramos ambos os desenhos possíveis.

Concordamos ainda que algumas formas de avaliação estatística podem superestimar diferenças entre os grupos. Entretanto, isso seria preocupante; principalmente se o risco obtido fosse marginal, e não robusto, como demonstram nossos dados. Uma análise utilizando razão de prevalência, ao invés de razão de chances, diminuiria o risco não corrigido de 4,2 para 3,6, valor este que ainda é superior ao reportado para hipotireoidismo, ${ }^{5}$ hipertireoidismo, ${ }^{6}$ nascimento nas ilhas britânicas, e em alguns estudos sobre diabetes. ${ }^{3,7}$ Por fim, ressaltamos que a metodologia empregada no nosso estudo (utilizando regressão logística e expondo a razão de chances) é semelhante à utilizada por Wang et al. ${ }^{3}$ em artigo publicado no Journal of Shoulder and Elbow, revista mais prestigiada no campo da Cirurgia de Ombro e Cotovelo.

Diante do exposto, e apesar das limitações inerentes aos estudos observacionais, mantemos a conviç̧ão de que a etnia asiática deve passar a fazer parte dos fatores de risco a serem considerados diante de um paciente com dor e rigidez articular no ombro.

Conflitos de Interesse

Os autores não têm conflitos de interesses para declarar.

Copyright $\odot 2019$ by Sociedade Brasileira License terms de Ortopedia e Traumatologia. Published by Thieme Revnter Publicações Ltda, Rio de Janeiro, Brazil 


\section{Referências}

1 Malavolta EA, Gracitelli MEC, Assunção JH, Pinto GMR, da Silveira AZF, Ferreira AA. Shoulder disorders in an outpatient clinic: an epidemiological study. Acta Ortop Bras 2017;25(03):78-80

2 Rizk TE, Pinals RS. Histocompatibility type and racial incidence in frozen shoulder. Arch Phys Med Rehabil 1984;65(01):33-34

3 Wang K, Ho V, Hunter-Smith DJ, Beh PS, Smith KM, Weber AB. Risk factors in idiopathic adhesive capsulitis: a case control study. J Shoulder Elbow Surg 2013;22(07):e24-e29

4 Malavolta EA, Gracitelli MEC, Ribeiro Pinto GMR, Freire da Silveira AZ, Assunção JH, Ferreira Neto AA. Asian ethnicity: a risk factor for adhesive capsulitis? Rev Bras Ortop 2018;53(05):602-606
5 Schiefer M, Teixeira PFS, Fontenelle C, et al. Prevalence of hypothyroidism in patients with frozen shoulder. J Shoulder Elbow Surg 2017;26(01):49-55

6 Huang SW, Lin JW, Wang WT, Wu CW, Liou TH, Lin HW. Hyperthyroidism is a risk factor for developing adhesive capsulitis of the shoulder: a nationwide longitudinal population-based study. Sci Rep 2014;4:4183

7 Lo SF, Chu SW, Muo CH, et al. Diabetes mellitus and accompanying hyperlipidemia are independent risk factors for adhesive capsulitis: a nationwide population-based cohort study (version 2). Rheumatol Int 2014;34(01):67-74 